\title{
Modeling an Integrated Network for Remote Patient Monitoring, Based on the Internet of Things for a More Preventive and Predictive Health System in West Africa
}

\author{
By M. H. Ahouandjinou ${ }^{1,2}$, D. Medenou ${ }^{1,2}$, L. Pecchia ${ }^{3}$, R. C. Houessouvo ${ }^{1,2}$, T. R. Jossou ${ }^{1,2}$ \\ ${ }^{1}$ Département de Génie Biomédical, Ecole Polytechnique d’Abomey-Calavi (Department of Biomedical Engineering, Ecole Polytechnique \\ d'Abomey-Calavi) \\ ${ }^{2}$ Laboratoire d'Electrotechnique de Télécommunications et d'Informatique Appliquée, Ecole Polytechnique d'Abomey-Calavi (Electrotechnical \\ Laboratory of Telecommunication and Applied Informatics, Ecole Polytechnique) Université d’Abomey-Calavi, Benin (University of Abomey- \\ Calavi, Benin) \\ ${ }^{3}$ School of Engineering, University of Warwick, Coventry, CV4 7AL, UK.
}

\section{ABSTRACT}

Background: As a result of globalization it is important to examine health systems organization in Africa to highlight the failures and propose possible solutions in terms of patient care.

Objective: Modeling was based on the Internet of Things (IoT) an Integrated Network for Monitoring Patient Data in West African Health Systems.

Methodology: To achieve the objective three steps were followed. (1) Identification of the different characteristics of IoT-based health surveillance systems, Wireless Body Area Network (WBAN) systems, and the physiological parameters that are monitorable on a patient. (2) The modeling of the architecture of West African health systems in the form of a cloud of technocenters. (3) Cross analysis between different IoT technologies, characteristics, and identification of any functional requirements. All this was based on wireless medical sensor networks in the WBAN systems.

Result: This work has been used to model health systems in Africa as a remote monitoring network for patients.

Conclusion: The implementation of this model of monitoring networks will be a tool to support large-scale decision-making for health systems in Africa. It will enable an information database for the West African health system.

Keywords - Modeling, Integrated Network, Internet of Things, health system, Technocentre.

Copyright (C) 2021. This is an open-access article distributed under the terms of the Creative Commons Attribution License (CC BY): Creative Commons - Attribution 4.0 International - CC BY 4.0. The use, distribution or reproduction in other forums is permitted, provided the original author(s) and the copyright owner(s) are credited and that the original publication in this journal is cited, in accordance with accepted academic practice. No use, distribution or reproduction is permitted which does not comply with these terms.

\section{RÉSUMÉ}

Contexte: Du fait de la globalisation des systèmes sanitaires, il est important d'examiner l'organisation des systèmes de santé en Afrique, sous l'angle de prise en charge des patients, pour mettre en évidence les défaillances et proposer des pistes de solutions. Objectif: Modéliser à base de l'internet des objets (IoT) un Réseau Intégré de Monitoring de données des patients dans les systèmes sanitaire de l'Afrique de l'ouest. 
Méthodologie: Pour y parvenir, trois étapes ont été suivies. (1) Le recensement les différents caractéristiques des systèmes de surveillance sanitaires basés sur IoT, des systèmes Wireless Body Area Network (WBAN) et les paramètres physiologiques monitorables sur un patient. (2) La modélisation de larchitecture des systèmes sanitaires ouest-africain sous forme d' un nuage de Technocentres. (3) L'analyse croisée entre les différentes technologies de l'IoT, les caractéristiques et les exigences fonctionelles identifiées. Tout ceci en se basant sur des réseaux de capteurs sans fil médicaux dans les systèmes WBAN.

Résultat: Ce travail a modélisé les systèmes sanitaires d'Afrique comme réseau de monitoring de données des patients.

Conclusion: La mise en œuvre de ce modèle de réseaux de monitoring consistera un outil d'aide à la prise de décision de grande envergure pour un système sanitaire en Afrique. Il permettra au système sanitaire ouest africain de disposer d'une banque de données d'information.

Mots-clés - Modélisation, Réseau Intégré, Internet des objets, Système de santé, Technocentre.

\section{INTRODUCTION}

The current challenges and goals of information and communication technologies (ICTs) are to provide effective and efficient healthcare. One of the latest advances in ICTs is the Internet of Things (IoT) providing global connectivity and management of sensors, devices, users, and information. The IoT concept provides the ability to search for information about a tagged object or person by browsing Internet addresses or a database entry that matches a particular active Radio Frequency Identification (RFID) with a detection function. In the last decade, wireless medical sensors, smartphones, and other mobile Wevices have attracted growing interest as tools that can wit can be used for personatheath

Some research has been done on the clinical applications of these technologies in remote healthcare surveillance architectures for long-term management, registration, and clinical access to patient physiological information

Based on these current technological advancements, it is easier to plan or schedule your physical examination, which is preceded by a period of a few days of continuous monitoring of your physiological state with less expensive wireless medical sensors. During this monitoring, wireless medical devices continually record signals correlating with the patient's important physiological parameters and sends them to a database of medical records. This scenario allows the medical professional (doctor and other) to have more information about the patient's state of health before the next appointment. Using this information and making it available to health professionals who also have access to a vast body of observational data for other individuals, the medical professional can data for other hividus, the medical professional can treatment regarding early intervention and particularly effective lifestyle changes that can impro quality of health. These techno advances have transformative impact on global health systems by dramatically reducing health costs and improving the speed and accuracy of diagnostics.

The vision presented previously from the technologica point of view has been available for some years now in several sanitary systems around the world not within the African health systems and especially West Africa despite the technology already on hand. The West African health system presents for the most part the same configuration and structuring inherited from their time as colonies.

In this article, we are particularly interested in modeling an architecture that takes into account the current structure of West African health systems while implementing the healthcare surveillance architecture.

\section{METHODOLOGY}

It is very important to choose the appropriate technique and methods in the literature search and data analysis. To ensure the integrity of the data, the means used to perform the analysis will depend on the information provided by the various search engines such as Google Scholar and scientific databases such as PubMed, Wiley, NCBI, IEEE Xplore, Scopus, and Web of Science. Google Scholar and IEEE Xplore are the two most used in our research.

The keywords used for data collection were: "IoT and Health Surveillance", "Internet of Things and Health System", "Remote Patient Monitoring with IoT". These three combinations of keywords were used on Google Schola for the documentary review.
This review of the literature revealed that the challenges of health surveillance are very topical. Most of the work has not been in favor of a particular health system from a country, region, or area depending on its configuration but has shown there is an opportunity presented by technological peral aspects of a patient's state of health including managing patient data, WBAN networks and architecture, security in health da man areas. ${ }^{3,4}$ All of militated in favor of the results obtained.

\section{RELATED WORK}

A total of 128 articles between 2010 and 2019 were found, with an emphasis on research between 2014 and 2016. The 128 articles were then sorted to rank those that best met the criteria of research. In the end, 34 articles were excluded and 94 were included as the subject of our study. The results are shown in Table 1.

TABLE 1.
\begin{tabular}{|c|c|c|}
\hline Year & $\begin{array}{c}\text { Number of articles found } \\
\text { per year }\end{array}$ & $\begin{array}{c}\text { Number of articles } \\
\text { excluded per year }\end{array}$ \\
\hline 2010 & 3 & 0 \\
\hline 2011 & 4 & 0 \\
\hline 2012 & 3 & 1 \\
\hline 2013 & 3 & 0 \\
\hline 2014 & 27 & 2 \\
\hline 2015 & 37 & 1 \\
\hline 2016 & 29 & 18 \\
\hline 2017 & 19 & 12 \\
\hline 2018 & 2 & 0 \\
\hline 2019 & 1 & 0 \\
\hline TOTAL & $\mathbf{1 2 8}$ & $\mathbf{3 4}$ \\
\hline
\end{tabular}

The IoT is of great potential interest for medical applications and healthcare. Many technologies are related to IoT. Technologies such as wireless medical body sensors, advanced healthcare systems, wearable sensors, cloudbased platform for wireless transfer, storage, and display of clinical data (see Table 2, in appendix) carry particular interest. In conclusion, we note that the challenges of any medical surveillance system lie in the proper design of the network architecture. In light of this, our work aims to model an integrated patient monitoring network (RIMP) in the West African health system, based on the IoT. This article presents the methodology adopted for the work, the results obtained, and the analysis, discussion, and perspectives envisaged.

RESULTS

Despite the specificities observed in each country, the health pyramid of West African countries generally includes first-level structures (dispensaries, health huts, etc.), so-called reference structures (general hospital), specialized structures (dedicated to a disability or illness), and university hospitals. In principle, so-called primary health care is the foundation of health systems, whose national health development programs (PNDS) stipulate that the structures responsible for it must cove $\mathrm{n}$ thousands of inhabitants in a given geographical area [Org]. Such a health pyramid has enormous advantages for mastering health data from scratch when it comes to diagnosis and care, so it has a modern remote monitoring architecture. For better monitoring of patients in African health systems, we propose an architecture integrating the different levels of each health system facilitated by a cloud of technocentres from remote monitoring networks. This would include survellance centers allowing centralized accessible health information.

IloT Architecture of an Integrated Patient Monitoring Network

Several physiological parameters can be monitored Sixteen different groups of physiological parameters can be monitored using IoT sensors placed at 17 differen locations on the patient's body.5 Figure 1 shows an outline of some of the physiological parameters ([A] blood pressure, [B] electrocardiogram, [C] pulse oximeter, [D] electromyogram, $[\mathrm{E}]$ inertia)

The IoT architecture of the Integrated Patient Monitoring Network shows the interaction of the different IoT components of our system and its network and computer technologies. The different IoTs in this architecture include intelligent medical sensors of different sizes and types that monitor patient health parameters and also process and record the raw data from the sensors. The transceiver modules of the medical sensors communicate with the base stations via a wireless interface. The most 
powerful base stations will act as data aggregators, well nodes, or gateways to servers. The different IoT Gateways work with the different types of devices and associated network protocols to provide overall connectivity.

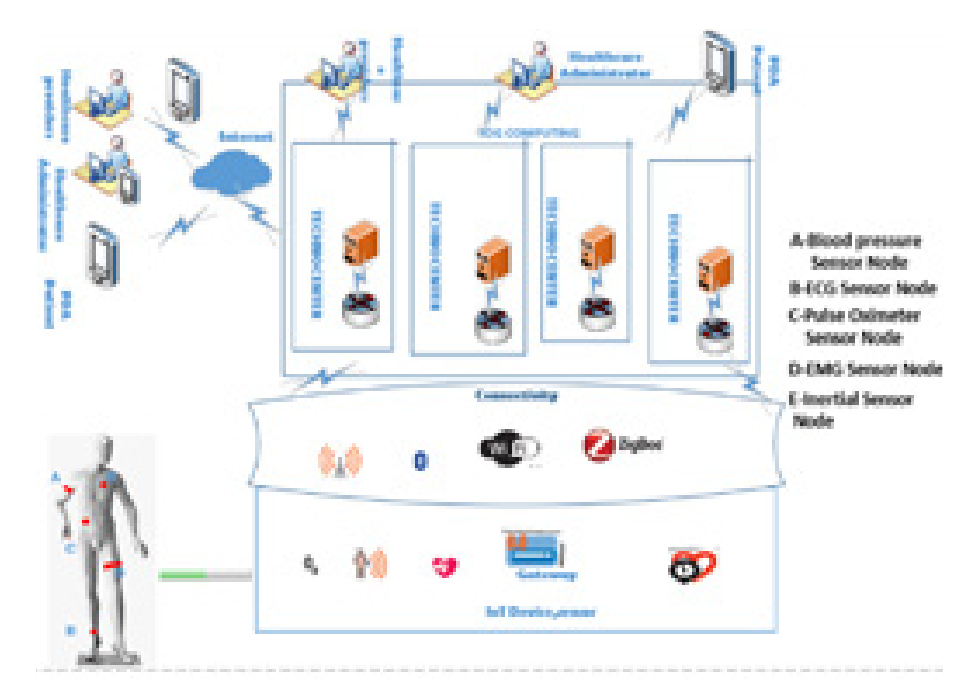

FIGURE 1. IoT architecture of an integrated patient monitoring network.

The integrated IoT patient monitoring architecture is made up of several levels. The first level is the IoT sensor level, which fits the patient with several sensors to measure the desired physiological parameters (EMG, (ECG, bug the architecture shows the connectivity elements. This level shows the symbols of the different communication networks used to route the data collected by the sensors to the treatment centers. Depending on the application, wifi, Bluetooth, or zigBee can be used to route measured physiological data to the sensor nodes and then to the treatment centers called here technocenters. Technocenters are data processing centers available at all levels of the health system including those in village health centers, district health centers, communal health centers, departments, and zones at the national level. These technocentres are

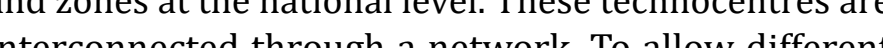
intercers requests from users of the network. To allowith different providers, the healthcare administrator and the patients, we are implementing a DNS service so the users can successfully request the data from the closest server with a different zone access from the internal and external users of the network. The patient's personal digital devices
(PDAs) will allow healthcare providers to capitalize on the capabilities in smartphones that patients already carry. Since these smartphones can be connected to the Internet through their GSM network, it would be enough to install eHealth applications allowing the patient's phones to receive and send the necessary information to and from receive and send (a) made for these smartphones regarding their specific
characteristics as needed.

Functional Architecture of the Hospital Platform

We propose the functional architecture of the hospital's platform detailed in Figure 2 to enable the West African health system to monitor patients effectively.

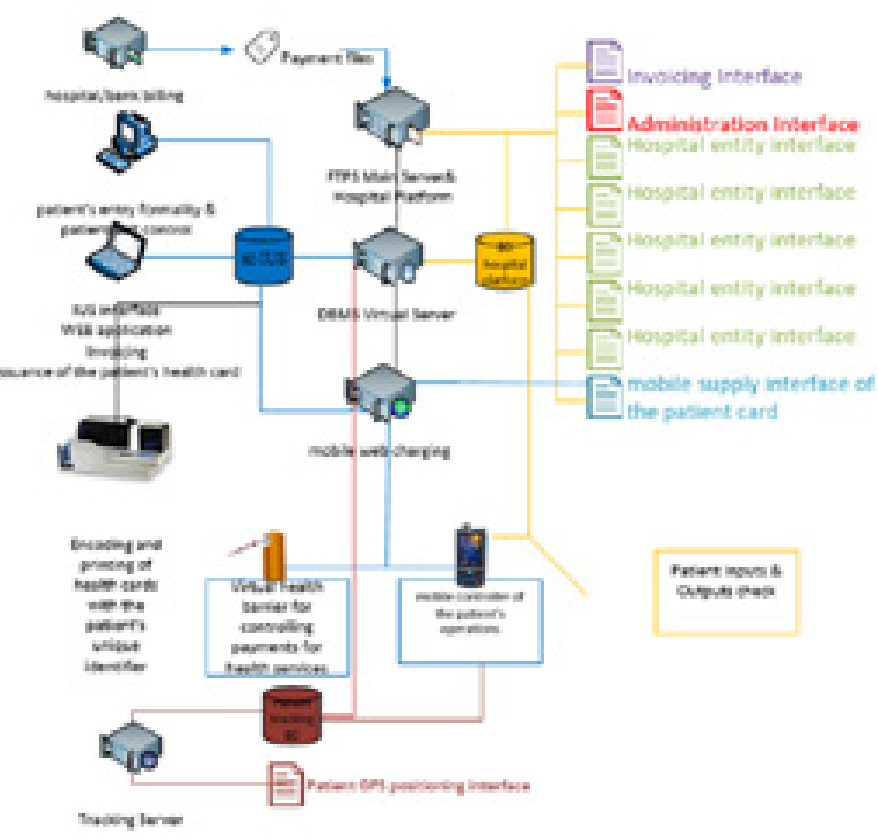

FIGURE 2. Functional architecture of the hospital platform.

The functional architecture of the hospital platform that we propose takes into account several aspects for the monitoring and the traceability of the patient inside and outside the hospital. We propose the use of the Country Unique Patient Health Identification (CIUS-P) for patients in the West African health system. This will allow a patient in Benin or any other African country to have a unique identity card from his country of origin. This new health card will make it cacto make it possible to know any health antecedent of a patient wherever they are. This multifunctional health card will also allow the payment of the patient's health services since it integrates a virtual account. The patient's localization feature will be integrated with the patient's CISU-P ard to find it thro card to fis eature will alow a paten's hospla kation to be known in real time. More interesting in this architecture is that the position of the patient is known even outside of the hospital in real time as long as they have the health card on them. The architecture of the platform integrates all the entities (surgery, medicine, emergency, laboratory ...) of the hospital so that the patient record can be seen by all (except for any access restrictions added as required).

\section{DISCUSSION}

Faced with the challenges of the West African health systems and in particular, the Beninese health system, which are (i) to provide quality health care to a growing population, (ii) to optimize the availability of health care personnel, and (iii) to utilize patient health data in a more predictive health system; we proposed in this work an integrated IoT architecture for patient monitoring and the functional architecture of the hospital platform whose implementation could revolutionize the West af 政 The implementation of this solution would go through several stages: first, choosing a health zone in Benin that has village, district, and communal health centers, departmental hospitals, and university hospitals. Once the expected positive results in this first zone were confirmed we would consider the extension of the architecture to other health zones.

Constraints of WBAN networks (i.e., scalability quality of service [QoS], energy consumption, wireless technology) will have to be taken into account ${ }^{6,7}$ Ther is a

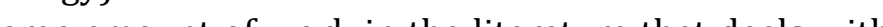
the application of WBANs in a healthcare setting ${ }^{89}$ This ( The fear ounes the characteristics and requirements acteristics and design factors.

Another consideration in the design of WBAN networks involves security requirements (WBAN and traditional networks have the same security requirements) ${ }^{10,11}$ However, this does not present a functional issue for the architecture of the hospital platform, which is the focus of our work. Moreover, we can see that the multitude of work in the literature does not consider a global architecture of a health system but often speaks of service architecture, while at the security level the security of patient and billing data will be considered when implementing the proposed solutions. Security theats or attacks, sing the s, such as proverting and locating activities, and hacking into security systems and alarns, can occur and must be taken into account. ${ }^{10,1}$ Also, data flow and network capacity are also among the parameters that have an impact on system performance. In this scenario, the choice of high-speed wireless technology offers advantages to meet the scalability of the network and increase the number of people being monitored. On the other hand, other technologies allow for lower powe consumption, but have higher delays (production) and/ or lower transfer rates. The technology chosen will therefore be a compre consumption As severa consumption. As several technologies are used in patien monitoring architectures to provide multiple services we started to identify all technologies used within the different services. On this basis, our work extends this knowledge by proposing the essential characteristics of any monitoring system adapted to the Beninese health system as well as the different possible positions where the sensors could be placed on a patient's body as mentioned in our previous work, ${ }^{5,13}$

CONCLUSION

In this work, we modeled West African health systems by proposing an loT architecture for patient monitoring an the functional architecture of the hospital platform. This model incorporates the CIUS-P which allows the patient information to be available in all areas across the West African health system. This architecture will allow the West African health system to respond to health challenges and Afrcan work will allow this architecture to be implemented in Benin to analyze its effect and any limitations. The implementation will occur through the choice of a health zone in Benin and take advantage of the unique identification database of the population set up, the project to interconnect all the health systems in Benin, the national data center, and 


\section{REFERENCES}

1. Kodali RK, Swamy G, and Lakshmi B. An implementation of IoT for healthcare in 2015 IEEE Recent Advances in Intelligent Computational Systems (RAICS), Trivandrum, Kerala, India; 2015. doi: 10.1109/RAICS.2015.7488451.

2. Naqishbandi T. Big data, CEP and IoT: Redefining holistic healthcare information systems and analytics. Int J Engineer Res 2015;4(1):6.

3. Sood SK and Mahajan I. Wearable IoT sensor based healthcare system for identifying and controlling chidoi: 10.1016/j.compind.2017.05.006.

4. Firouzi F, et al. Internet-of-Things and big data for smarter healthcare: From device to architecture, applications and analytics. Future Gen Computer Sys 2018;78:583-86, janv. doi: 10.1016/j.future.2017.09.016.

5. Medenou D, Ahouandjinou MH, Piaggio D, et al. New intelligent network approach for monitoring physilogical parameters: the case of Benin. Health Technol 2020. doi: 10.1007/s12553-020-00418-5.

6. Charlton $\mathrm{S}$, et al. Architecture for field upgrade of a health monitoring system. US8978026B2; 2015.

7. Akyildiz IF, Melodia T, and Chowdhury KR. A survey on wireless multimedia sensor networks. Comp Network 2007;51(4)921-60. doi: 10.1016/j.comnet.2006.10.002.

8. Gogate U and Bakal JW. Smart healthcare monitoring system based on wireless sensor networks in 2016 International Conference on Computing, Analytics and Security Trends (CAST), Pune, India; 2016. doi: 10.1109/CAST.2016.7915037.

9. Goyal A, et al. Smart home health monitoring system for predicting type 2 diabetes and hypertension.J King Saud University Comput Info Sci 2020; doi: 10.1016/j. jksuci.2020.01.010.

10.Sathya D. Secured remote health monitoring system. Healthc Technol Lett 2020;4(6):228-32. 10.1049/ htl.2017.0033. Available at: https://sci-hub.tw/10.1049/ htl.2017.0033. survey on health monitoring systems for health smart homes. Internat J Industr Ergonom 2018;66:26-56. doi: 10.1016/j.ergon.2018.02.002

12.Bourennane W. Étude et conception d'un système de télésurveillance et de détection de situations critiques par suivi actimétrique des personnes à risques en milie indoor et outdoor ", phdthesis, Université Toulouse le Mirail - Toulouse II; 2013.

13. Medenou D, Ahouandjinou MH, and Pecchia L. National Integrated Network For Remote Monitoring Of Patients In Benin. CEUR Workshop Proceedings 2544 CEUR-WS.org; 2020.

14.Jara AJ, Alcolea AF, Zamora MA, et al. Drugs interaction checker based on IoT. In 2010 Internet of Things (IOT) Tokyo, Japan; 2010. doi: 10.1109/IOT.2010.5678458.

15.Bui $\mathrm{N}$ and Zorzi M. Health care applications: a solution based on the internet of things. In Proceedings of the 4th International Symposium on Applied Sciences in Biomedical and Communication Technologies - ISABEL'11 Barcelona, Spain; 2011. doi: 10.1145/2093698.2093829.

16. Rohokale VM, Prasad NR, and Prasad N. A cooperative Internet of Things (IoT) for rural healthcare monitoring and control. In 2011 2nd International Conference on Wireless Communication, Vehicular Technology, Information Theory and Aerospace \& Electronic Systems Technology (Wireless VITAE), Chennai, India 2011. doi: 10.1109/WIRELESSVITAE.2011.5940920

17.Zhao W, Wang C, and Nakahira Y. Medical application on Internet of Things. In IET International Conference on Communication Technology and Application (ICCTA 2011), Beijing, China; 2011. doi: 10.1049/cp.2011.0751.

18.Chen Y-K. Challenges and opportunities of internet of things. In 17th Asia and South Pacific Design Automation Conference, Sydney, Australia; 2012. doi: 10.1109/ ASPDAC.2012.6164978.

19.Doukas C, Maglogiannis I, Koufi V, et al. Enabling data protection through PKI encryption in IoT m-Health devices. In 2012 IEEE 12th International Conference on Bioinformatics \& Bioengineering (BIBE), Larnaca, Cyprus; 2012. doi: 10.1109/BIBE.2012.6399701.
20.Tarouco LMR, et al. Internet of Things in healthcare: Interoperatibility and security issues. In 2012 IEEE International Conference on Communications (ICC), Ottawa, ON, Canada; 2012. doi: 10.1109/ICC.2012.6364830.

21.Gubbi J, Buyya R, Marusic S, Palaniswami M. Internet of Things (IoT): A vision, architectural elements, and future directions. Future Gen Comput Syst 2013;29(7)1645-60 doi: 10.1016/j.future.2013.01.010.

22.Turcu CE, and Turcu CO. Internet of Things as Key Enabler for Sustainable Healthcare Delivery. Procedia Soc Behav Sci 2013;73:251-56. doi: 10.1016/j. sbspro.2013.02.049.

23. Fan YJ, Yin YH, Xu LD, et al. IoT-Based Smart Rehabilitation System. IEEE Transact Indust Infor 2014;10(2):1568-77. doi: 10.1109/TII.2014.2302583.

24.Yang G, et al. A Health-IoT Platform Based on the Integration of Intelligent Packaging, Unobtrusive BioSensor, and Intelligent Medicine Box. IEEE Transact Indust Inform 2014;10(4):2180-91. doi: 10.1109/ TII.2014.2307795.

25. Yang L, Ge Y, Li W, et al. A home mobile healthcare system for wheelchair users. (:unav); 2014. doi: 10.1109/ cscwd.2014.6846914.

26.Xu LD, He W, Li S. Internet of Things in Industries: A Survey. IEEE Transact Indust Informat 2014;10(4):2233-43. doi: 10.1109/tii.2014.2300753.

27.Suresh P Daniel JV, Parthasarathy V, and Aswathy RH. A state of the art review on the Internet of Things (IoT) history, technology and fields of deployment. (:unav); 2014. doi: 10.1109/icsemr.2014.7043637.

28.Singh D, Tripathi G, and Jara AJ. A survey of Internet-ofThings: Future vision, architecture, challenges vices. (unav); 2014. doi: 10.1109/wf-iot 2014.6803174.

29.Ray PP. Home Health Hub Internet of Things (H3IoT): An architectural framework for monitoring health of elderly people. (:unav); 2014. doi: 10.1109/ icsemr.2014.7043542.

30. Rasid MFA, et al. Embedded gateway services for Internet of Things applications in ubiquitous healthcare. (:unav); 2014. doi: 10.1109/icoict.2014.6914055.
31.Li S, Xu LD, and Zhao S. The internet of things: a survey. Information Systems Frontiers 2015;17(2):243-59 avr. doi: 10.1007/s10796-014-9492-7.

32.Lee BM and Ouyang J. Intelligent Healthcare Service by using Collaborations between IoT Personal Health Devices. Internat J Bio-Sci Bio-Technol 2014;6(1)155-64. doi: 10.14257/ijbsbt.2014.6.1.17

33. Kupwade H, and Patil R. Big Data Security and Privacy Issues in Healthcare. (:unav); doi: 10.1109/bigdata. congress.2014.112.

34.Kulkarni A and Sathe S. Healthcare applications of the Internet of Things: A Review 2014;5(4):2014.

35. Hiremath S, Yang G, and Mankodiya K. Wearable Internet of Things: Concept, Architectural Components and Promises for Person-Centered Healthcare. At the 4th International Conference on Wireless Mobile Communication and Healthcare. Transforming healthcare through innovations in mobile and wireles technologies. Athens, Greece; 2014. doi: 10.4108/icst. mobihealth.2014.257440.

36. Granados J, Rahmani A-M Nikander P, et al. Towards Energy-Efficient HealthCare: an Internet-of-Things Architecture Using Intelligent Gateways. At the 4th International Conference on Wireless Mobile Communication and Healthcare. Transforming healthcare through innovations in mobile and wireless technologies. Athens, Greece, 2014, doi: 10.4108/icst. mobihealth.2014.257394.

37.Gia TN, Thanigaivelan NK, Rahmani A.-M, et al. Customizing 6LoWPAN networks towards Internet-of-Things based ubiquitous healthcare systems. In NORCHIP, Tampere; 2014. doi: 10.1109/NORCHIP.2014.7004716.

38.Zhou W and Piramuthu S. Security/privacy of wearable fitness tracking IoT devices. 2014 9th Iberian Conference on Information Systems and Technologies (CISTI), Barcelona, Spain; 2014. doi: 10.1109/ CISTI.2014.6877073.

39.Fernandez F and Pallis G. Opportunities and challenges of the Internet of Things for healthcare. The 4th International Conference on Wireless Mobile Communication and Healthcare. Transforming healthcare through innovations in mobile and wireless 
technologies. Athens, Greece; 2014. doi: 10.4108/icst. mobihealth.2014.257276.

40.Chiuchisan I, Costin H-N, and Geman O. Adopting the Internet of Things technologies in health care systems. (:unav); 2014. doi: 10.1109/icepe.2014.6969965.

41.Amendola S, Lodato R, Manzari S, et al. RFID Technology for IoT-Based Personal Healthcare in Smart Spaces. IEEE Internet of Things Journal 2014:1(2):144-52. doi: 10.1109/JIOT.2014.2313981.

42.Elhoseny M, Ramirez-Gonzalez G, Abu-Elnasr OM, et al. Secure Medical Data Transmission Model for IoT-Based Healthcare Systems. IEEE Access 2018;6:20596-608. doi: 10.1109/ACCESS.2018.2817615.

43.Firouzi $\mathrm{F}$ et al. Internet-of-Things and big data for smarter healthcare: From device to architecture, applications and analytics. Future Gen Comput Syst 2018;78:83-586. doi: 10.1016/j.future.2017.09.016.

44.Rahmani AN, et al. Exploiting smart e-Health gateways at the edge of healthcare Internet-of-Things: A fog computing approach. Future Gen Comput Syst 2018:78:641-58. doi: 10.1016/jfuture.2017.02.014.

45.Ullah F, Habib MA, Farhan M, et al. Semantic interoperability for big-data in heterogeneous IoT infrastructure for healthcare. Sustainable Cities Soc 2017;34:90-96. doi: 10.1016/j.scs.2017.06.010

46.Sood SK and Mahajan I. Wearable IoT sensor based healthcare system for identifying and controlling hikungunya virus. Comput Industry 2017:9:33-44. doi: 10.1016/j.compind.2017.05.006.

47.Woo MW, Lee J, and Park K. A reliable IoT system for Personal Healthcare Devices. Future Gen Comput Syst 2018:78:626-40. doi: 10.1016/j future 2017.04.004.

48.Verma P, Sood SK, and Kalra S. Cloud-centric IoT based student healthcare monitoring framework. J Ambient Intell Human Comput 2018;9(5):1293-309. doi: 10.1007/s12652-017-0520-6

49.Wu T, Wu F, Redoute JM, and Yuce MR. An Autonomous Wireless Body Area Network Implementation Towards IoT Connected Healthcare Applications. IEEE Access 2017;5:11413-22. doi: 10.1109/ACCESS.2017.2716344.

50.Kaur MJ and Maheshwari P. Building smart cities applications using IoT and cloud-based architectures. 2016
International Conference on Industrial Informatics and Computer Systems (CIICS), Sharjah, Dubai, United Arab Emirates; 2016. doi: 10.1109/ICCSII.2016.7462433.

51.Moosavi SR, et al. End-to-end security scheme for mobility enabled healthcare Internet of Things. Future Gen Comput Syst 2016;64:108-24, nov. 2016, do 10.1016/j.future.2016.02.020

52. Kang H-W, Kim D-M, and Koh S-J. ISO/IEEE 11073-Based Healthcare Services over IoT Platform Using 6LoWPAN and BLE: Architecture and Experimentation. (:unav); 2016. doi: 10.1109 /nana.2016.26.

53.Iqbal MA and Bayoumi M. Secure End-to-End key establishment protocol for resource-constrained healthcare sensors in the context of IoT. (:unav); 2016 doi: 10.1109/hpcsim.2016.7568379.

54.Hossain MS. and Muhammad G. Cloud-assisted Industrial Internet of Things (IIoT) - Enabled framework fo health monitoring. Comput Network 2016;101:192-202 doi: 10.1016/j.comnet.2016.01.009.

55. Hashemi SH, Faghri F, Rausch P, et al. World of Empowered IoT Users. (:unav); 2016. doi: 10.1109/iotdi.2015.39.

56.Gope P and Hwang T. BSN-Care: A Secure IoT-Based Modern Healthcare System Using Body Sensor Network IEEE Sensors J 2016;16(5):1368-76. doi: 10.1109/ JSEN.2015.2502401.

57.Corno F, De Russis L, and Roffarello AM. A Healthcare Support System for Assisted Living Facilities: An IoT Solution. (:unav); 2016. doi: 10.1109/compsac.2016.29.

58.Basanta H, Huang YP, et Lee T-T. Intuitive IoT-based H2U healthcare system for elderly people. 2016 IEE 13th International Conference on Networking, Sensing, and Control (ICNSC), Mexico City, Mexico; 2016. doi: 10.1109/ICNSC.2016.7479018.

59.Azimi I, Anzanpour A, Rahmani AM, et al. Self-aware Early Warning Score System for IoT-Based Personalized Healthcare. eHealth $360^{\circ}$ 2017;181:49-55.

60.Darshan KR and Anandakumar KR. A comprehensive review on usage of Internet of Things (IoT) in healthcare system. 2015 International Conference on Emerging Research in Electronics, Computer Science and Technology (ICERECT), Mandya, India; 2015. do 10.1109/ERECT.2015.7499001.
61.Datta SK, Bonnet C, and Gyrard RP, et al. Applying Internet of Things for personalized healthcare in smart homes. (:unav); 2015. doi: 10.1109/wocc.2015.7346198.

62. Deng Z, Yang P, Zhao Y, et al. Life-Logging Data Aggregation Solution for Interdisciplinary Healthcare Research and Collaboration. (:unav); 2015. doi: 10.1109/cit/ ucc/dasc/picom.2015.342.

63.Gia TN, Jiang M, Rahmani A-M, et al. Fog Computing in Healthcare Internet of Things: A Case Study on ECG Feature Extraction. (:unav); 2015. doi: 10.1109/cit/ iucc/dasc/picom.2015.51.

64.Gong T, Huang H, Li P, et al. A Medical Healthcare System for Privacy Protection Based on IoT. 2015 Seventh International Symposium on Parallel Architectures, Algorithms and Programming (PAAP), Nanjing, China; 2015. doi: 10.1109/PAAP.2015.48.

65.Gupta MSD, Patchava V, and Menezes V. Healthcare based on loT using Raspberry Pi. p. 4, 2015.

66. Hassanalieragh M, et al. Health Monitoring and Mangement Using Internet-of-Things (IoT) Sensing with Cloud-Based Processing: Oppo (:unav); 2015. doi: 10.1109/scc.2015.47.

67.He D and Zeadally S. An Analysis of RFID Authentication Schemes for Internet of Things in Healthcare Environment Using Elliptic Curve Cryptography. IEEE Internet Things J 2015;2(1):72-83. doi: 10.1109/ jiot.2014.2360121.

68.Hou J-L and Yeh K-H. Novel Authentication Schemes for IoT Based Healthcare Systems. Internat J Distrib Sensor Network 2015;11. doi: 10.1155/2015/183659.

69. Kodali RK, Swamy G. An implementation of IoT for healthcare $"$ in 2015 IEEE Recent Advances in Intelhealt ligent Compu 2015 . do: 10.1109/RAICS.2015.748451.

70. Laplante PA and Laplante NL. A Structured approach for describing healthcare applications for the Internet of Things. (:unav); 2015. doi: 10.1109/wf-iot.2015.7389125.
71.Giorgos KEIB, Antonis B. Internet of Things For an AgeFriendly Healthcare. Studies Health Technol Informat 2015;587-91. doi: 10.3233/978-1-61499-512-8-587.

72.Lee BM. Personalized Service Model for Sharing Medical Devices in IoT Health-Platform 2015;180-82. doi 10.14257/astl.2015.99.44.

73.Maksimovic M, Vujovic V, and Perisic B. A custom Internet of Things healthcare system. (:unav); 2015. doi: 10.1109/cisti.2015.7170415

74. Moosavi SR, et al. SEA: A Secure and Efficient Authentication and Authorization Architecture for IoT-Based Healthcare Using Smart Gateways. Procedia Comput Sci 2015;52:452-59. doi: 10.1016/j.procs.2015.05.013.

75. Naqishbandi T. Big Data, CEP and IoT: Redefining Holistic Healthcare Information Systems and Analytics. Internat J Engineer Res 2015;4(01):7.

76.Khoi NM, Saguna S, Mitra K, and Ahlund C. IReHMo: An efficient IoT-based remote health monitoring system for smart regions. (:unav);2015. doi: 10.1109/ healthcom.2015.7454565.

77.Rahmani A-M, et al. Smart e-Health Gateway: Bringing intelligence to Internet-of-Things based ubiquitous healthcare systems. 12th Annual IEEE Consumer Communications and Networking Conference (CCNC), Las Vegas, NV, USA; 2015. doi: 10.1109/CCNC.2015.7158084.

78. Riazul Islam SM, Kwak D, Humaun M, et al. The Internet of Things for Health Care: A Comprehensive Survey. IEEE Access 2015;3: 678-708. doi: 10.1109/ ACCESS.2015.2437951.

79.Shi Y, Ding G, Wang H, et al. The fog computing service for healthcare. 2015 2nd International Symposium on Future Information and Communication Technologies for Ubiquitous HealthCare (Ubi-HealthTech) Beijing Chic 2015. doi: 10.1109/Ubi-HealthTech.2015.7203325.

80.Ugrenovic D and Gardasevic G. CoAP protocol for Web-based monitoring in IoT healthcare applications. 2015 23rd Telecommunications Forum Telfor (TELFOR), Belgrade, Serbia; 2015:79-82. doi: 10.1109/ TELFOR.2015.7377418. 
APPENDIX

\begin{tabular}{|c|c|c|}
\hline $\mathbf{N}^{\circ}$ & Ref. & Aspect covered \\
\hline 1 & [14] & $\begin{array}{l}\text { Put in place a solution to address drug issues based on IoT technologies like smartphones and the Web } \\
\text { to support ubiquitous access, 6LoWPAN technology for ubiquitous patient data collection, sensors and } \\
\text { hospitals, RFID / NFC (Near Field Communication) and barcode identification technologies. }\end{array}$ \\
\hline 2 & [15] & $\begin{array}{l}\text { Propose IoT Communication Framework as Primary Tool for Healthcare Applications Spread Around the } \\
\text { World. They presented the IoT protocol stack and the benefits it brings to health care scenarios. }\end{array}$ \\
\hline 3 & [16] & $\begin{array}{l}\text { Proposed a cooperative approach of IoT to improve the monitoring and control the health of rural and } \\
\text { poor human health parameters. }\end{array}$ \\
\hline 4 & [17] & $\begin{array}{l}\text { Analyze the possibility and related issues of providing advanced services for human health management in } \\
\text { the real world of medical technology on IoT. }\end{array}$ \\
\hline 5 & [18] & Shows an overview of the challenges and opportunities of IoT. \\
\hline 6 & [19] & $\begin{array}{l}\text { Present a prototype of a cloud-based system, compliant with the IoT concept. Including those related to the } \\
\text { authentication of entities and data confidentiality. The proposed system manages the data collected by the } \\
\text { portable sensors and transmitted them to a gateway using cloud infrastructure techniques. }\end{array}$ \\
\hline 7 & [20] & $\begin{array}{l}\text { Worked on interoperability and security issues related to the limitations of devices used in the IoT, } \\
\text { preventing their proper use in health systems. }\end{array}$ \\
\hline 8 & [21] & $\begin{array}{l}\text { Presents with a cloud-centric vision for the global implementation of the IoT. The authors' work allowed to } \\
\text { make a cloud implementation using Aneka, based on the interaction of private and public Clouds }\end{array}$ \\
\hline 9 & [22] & $\begin{array}{c}\text { Showed how RFID, multi-agent technologies and the IoT can be used to allow people access to affordable } \\
\text { and quality health services. The authors show that using the IoT and multi-agent technologies can reduce } \\
\text { medical errors, improve patient safety, and optimize healthcare processes. }\end{array}$ \\
\hline 10 & [23] & Presents an ontology-based design methodology for intelligent reeducation systems in IoT. \\
\hline 11 & [24] & $\begin{array}{l}\text { Worked on home health services based on the IoT. They proposed a smart home platform, named iHome } \\
\text { Health-IoT. }\end{array}$ \\
\hline 12 & [25] & $\begin{array}{l}\text { Presented a mobile home health system (mHealth) for wheelchair users, based on emerging technologies of } \\
\text { the IoT. The authors focused on the proposed system architecture and the design of Wireless Body Sensor } \\
\text { Networks (WBSN). }\end{array}$ \\
\hline 13 & [26] & $\begin{array}{l}\text { Review the current research on the IoT, generic key technologies, key IoT applications in industries, and } \\
\text { identify trends and challenges in research. }\end{array}$ \\
\hline 14 & [27] & $\begin{array}{l}\text { Structured in this work a review of the state of the art on IoT by bringing out its history, the different } \\
\text { technologies of IoT and its different applications. }\end{array}$ \\
\hline 15 & [28] & Present a novel architecture model for IoT with the help of Semantic Fusion Model (SFM). \\
\hline 16 & [29] & $\begin{array}{l}\text { Present H3IoT, a new architectural framework for a home health center based on the Internet of Things, } \\
\text { which aims to monitor the health of elderly people at home. }\end{array}$ \\
\hline \multicolumn{3}{|c|}{17} \\
\hline & [30] & $\begin{array}{l}\text { Present the integrated services that are part of a ubiquitous health system that enables automated and } \\
\text { intelligent monitoring and utilizing IP and Internet connectivity for end-to-end communication. }\end{array}$ \\
\hline 18 & [31] & $\begin{array}{l}\text { Present the definitions, architecture, fundamental technologies, and applications of IoT. Various definitions } \\
\text { of IoT are introduced, emerging techniques for the implementation of IoT are discussed. }\end{array}$ \\
\hline
\end{tabular}

Aspect covered

\begin{tabular}{|c|c|c|}
\hline $\mathbf{N}^{\circ}$ & Ref. & Aspect covered \\
\hline 19 & [32] & $\begin{array}{l}\text { Worked on self-care through IoT through personal health devices. By introducing the collaborative } \\
\text { protocol that transfers risk factors between IoT personal health devices. }\end{array}$ \\
\hline 20 & [33] & $\begin{array}{l}\text { Worked on data security and confidentiality in the healthcare sector given the increasing data growth in } \\
\text { this sector. }\end{array}$ \\
\hline 21 & [34] & $\begin{array}{l}\text { Examined the applications of IoT in personalized health care to obtain excellent health care at affordable } \\
\text { costs through detection and wireless techniques. }\end{array}$ \\
\hline 22 & [35] & $\begin{array}{l}\text { Worked on the concept, the architectural components of the wearable IoT because of their detection and } \\
\text { communication capabilities. }\end{array}$ \\
\hline 23 & [36] & $\begin{array}{l}\text { Worked on the energy efficiency in the architectures of the IoT in exploiting the advantages related to the } \\
\text { standard POE (Power over Ethernet). }\end{array}$ \\
\hline 24 & [37] & $\begin{array}{l}\text { Worked on an IoT architecture and system implementation for health applications to offer a simple and } \\
\text { economical way to analyze and monitor health data in real time. }\end{array}$ \\
\hline 25 & [38] & $\begin{array}{l}\text { Worked on the security and confidentiality of tracking physical conditions through portable connected } \\
\text { objects. }\end{array}$ \\
\hline 26 & [39] & Have worked on the different opportunities and challenges of IoT. \\
\hline 27 & [40] & $\begin{array}{l}\text { Worked on the development of a general architecture for IoT-based health care systems to ensure and } \\
\text { increase patient safety, quality of life, and other health care activities. }\end{array}$ \\
\hline 28 & [41] & Worked on the use of RFID for personal health care based on the IoT. \\
\hline 29 & [42] & Secure medical data transmission model in health systems based on IoT. \\
\hline 30 & [43] & IoT and Big Data for intelligent healthcare, individualized telehealth to enable healthier lifestyles. \\
\hline 31 & [44] & $\begin{array}{l}\text { Operation of the gateway between the network of medical sensors and the Internet in a health care } \\
\text { surveillance system to offer several services. }\end{array}$ \\
\hline 32 & [45] & A semantic interoperability model for Big Data in the IoT. \\
\hline 33 & [46] & IoT architecture to identify and control the Chikungunya virus. \\
\hline 34 & [47] & a reliable IoT architecture based on oneM2M for personal healthcare devices \\
\hline 35 & [48] & IoT-based healthcare surveillance architecture to move to proactive and preventive healthcare. \\
\hline 36 & [49] & WBAN sanl fil < Au: Please clarify sanl fil> network based on IoT for healthcare. \\
\hline 37 & [50] & Smart city cloud platform with IoT \\
\hline 38 & [51] & Three-level IoT architecture composed of the device layer, the fog layer, and the cloud layer. \\
\hline 39 & [52] & $\begin{array}{l}\text { A new architecture for health services based on ISO / IEEE } 11073 \text { on the IoT platform. The proposed } \\
\text { architecture meets oneM2M and ISO / IEEE 11073. Standards with a stack of protocols for constrained } \\
\text { healthcare devices on the BLE network. }\end{array}$ \\
\hline 40 & [53] & $\begin{array}{l}\text { A cooperative key establishment protocol to create a secure end-to-end connection for resource-limited } \\
\text { sensor nodes with any remote server or entity. Security analysis and performance appraisals prove to be } \\
\text { a considerable improvement in security as well as protocol resilience against known attacks and security } \\
\text { breaches. }\end{array}$ \\
\hline 441 & {$[54]$} & $\begin{array}{l}\text { A cloud-integrated Health IoT monitoring framework, where health data is watermarked before being sent } \\
\text { to the cloud for secure, high-quality, health monitoring. }\end{array}$ \\
\hline 42 & [55] & $\begin{array}{l}\text { A new user-oriented world of IoT. In this world, users are empowered by their ability to control access } \\
\text { to the data that has been knowingly or unknowingly generated and belongs to them. This data can be } \\
\text { equested by other users and organizations to be analyzed collectively and potentially bring value to society }\end{array}$ \\
\hline
\end{tabular}


Ahouandjinou, Medenou, Pecchia, Houessouvo, Jossou: Modeling an Integrated Network for Remote Patient Monitoring, Based on the Internet of Things for a More Preventive and Predictive Health System in West Africa

\begin{tabular}{|c|c|c|}
\hline $\mathbf{N}^{\circ}$ & Ref. & Aspect covered \\
\hline 43 & {$[56]$} & $\begin{array}{l}\text { security and confidentiality issues in health applications using the body sensor network (BSN). They } \\
\text { proposed an IoT-based secure health system using BSN, called BSN-Care, which can effectively meet } \\
\text { various security requirements of the BSN-based health system. }\end{array}$ \\
\hline 44 & [57] & $\begin{array}{l}\text { An IoT system capable of improving assistance requests and the detection of anomalies in an ALF }<\text { AU: } \\
\text { Please expand ALF }>\text { using portable devices. With this healthcare support system, caregivers can be } \\
\text { automatically alerted to potentially dangerous situations that occur to residents while they are out of sight. } \\
\text { The system design focused mainly on portability and ubiquity. }\end{array}$ \\
\hline 45 & [58] & $\begin{array}{l}\text { An IoT H2U predictive health care system to provide early treatment and detect danger signs early enough } \\
\text { to avoid the need for hospitalization. Hospital stay is minimized and doctors and nurses can be connected } \\
\text { and monitor patients based on the report generated by the sensors in real time and daily clinical updates } \\
\text { by the patient on the base server of data. Interaction via this IoT system is quite profitable and guarantees a } \\
\text { higher level of security in terms of communication. }\end{array}$ \\
\hline 46 & [59] & $\begin{array}{l}\text { Exploited the concept of self-awareness to create a personalized EWS Alert Score System }<\text { AU: Please } \\
\text { expand EWS }>\text { based on the IoT. The system is designed to be adaptive in various situations and to be able } \\
\text { to be automatically personalized according to the needs of the patient. }\end{array}$ \\
\hline 47 & {$[60]$} & $\begin{array}{l}\text { The use of the Internet of Things for the efficiency of the health system by exploring the challenges of these } \\
\text { systems. Their work provided an architecture / methodology for extracting information from health care } \\
\text { data. }\end{array}$ \\
\hline 48 & [61] & $\begin{array}{l}\text { The use of the Internet of Things for the efficiency of the health system by exploring the challenges of these } \\
\text { systems. Their work provided an architecture / methodology for extracting information from healthcare } \\
\text { data. }\end{array}$ \\
\hline 49 & {$[62]$} & $\begin{array}{l}\text { Implementation of a data aggregation solution for interdisciplinary healthcare research after comparing the } \\
\text { different existing IoT applications which focus mostly on the physical condition of people. They proposed } \\
\text { the architecture for monitoring healthcare with multiple functions for the acquisition of bio-signals (EEG, } \\
\text { EMG, ECG) }\end{array}$ \\
\hline 50 & [63] & $\begin{array}{l}\text { Computer haze in the IoT in health surveillance systems by exploiting the concept of calculating fog with } \\
\text { intelligent gateways applied to ECG signals. }\end{array}$ \\
\hline 51 & {$[64]$} & $\begin{array}{l}\text { The security of private information in a health care information system using the Internet of Things. The } \\
\text { authors have implemented an algorithm to secure health data. a prototype based on both software and } \\
\text { hardware has also been implemented. }\end{array}$ \\
\hline 52 & [65] & $\begin{array}{l}\text { Implementing a system for continuous monitoring of the EEG and other vital parameters using algorithms } \\
\text { based on Raspberry pi. The Raspberry } \mathrm{P} i \text { is a small computer with an integrated microprocessor card. }\end{array}$ \\
\hline 53 & [66] & $\begin{array}{l}\text { The different opportunities and benefits of using the IoT in remote health monitoring. the use of portable } \\
\text { sensors is necessary to record data in various environments for health surveillance. }\end{array}$ \\
\hline 54 & [67] & $\begin{array}{l}\text { The security requirements of RFID authentication schemes for Internet of Things-based healthcare } \\
\text { surveillance systems. The authors presented the overall architecture of the RFID-based authentication } \\
\text { system and their requirements }\end{array}$ \\
\hline 55 & [68] & $\begin{array}{l}\text { The security of IoT-based health systems. They proposed a communication architecture based on sensors } \\
\text { in health service systems integrating a secure authentication scheme and a protocol for the coexistence of } \\
\text { multiple health systems operating under the technology of the IoT. }\end{array}$ \\
\hline 56 & [69] & implementation of the IoT in a hospital system using ZigBee which is a mesh protocol. \\
\hline 57 & [70] & $\begin{array}{l}\text { The classification and structuring of IoT applications in healthcare. The results of the authors' work show } \\
\text { that applications in the health of the IoT can be classified into three categories of systems. }\end{array}$ \\
\hline 58 & [71] & new approach to the IoT with devices compatible with IoT thanks to the XMPP protocol. \\
\hline
\end{tabular}

Ahouandjinou, Medenou, Pecchia, Houessouvo, Jossou: Modeling an Integrated Network for Remote Patient Monitoring. Based on the Internet of Things for a More Preventive and Predictive Health System in West Africa

\begin{tabular}{|c|c|c|c|}
\hline $\mathbf{N}^{\circ}$ & Ref. & Aspect covered \\
\hline 59 & {$[72]$} & $\begin{array}{c}\text { Share the use of medical equipment used in a health service or office through the IoT. They proposed a } \\
\text { personalized health service model that can be used in family or public offices. }\end{array}$ \\
\hline 60 & {$[73]$} & $\begin{array}{c}\text { Health self-management systems for support. They proposed the establishment of a personal health } \\
\text { monitoring system adapted to the needs of the user (Do-It-Yourself). }\end{array}$ \\
\hline 61 & {$[74]$} & $\begin{array}{c}\text { Medical data capture and confidentiality architectures. The work allowed the authors to develop an } \\
\text { architecture of authentication and authorization that is secure and efficient for healthcare based on IoT } \\
\text { while taking into account the constraints of the resources of medical sensors. }\end{array}$ \\
\hline 62 & {$[75]$} & $\begin{array}{c}\text { Big Data technologies, IoT and complex event processing (CEP) and their importance in the healthcare } \\
\text { system revolution. }\end{array}$ \\
\hline 63 & {$[76]$} & $\begin{array}{c}\text { A remote health monitoring system based on IoT, after identifying the main network requirements and } \\
\text { studying the CoAP, MQTT and HTTP protocols. }\end{array}$ \\
\hline 64 & {$[77]$} & $\begin{array}{c}\text { Smart gateways in e-health which is a transition point between the sensor and Internet networks. They } \\
\text { proposed an intelligent e-health gateway betwen the sensor and the Internet for remote monitoring of } \\
\text { health care. }\end{array}$ \\
\hline 65 & {$[78]$} & $\begin{array}{c}\text { An intelligent collaborative security model to minimize security risks; and propose how different } \\
\text { innovations such as big data, ambient intelligence and portable devices can be used in healthcare } \\
\text { establishments. }\end{array}$ \\
\hline 66 & {$[79]$} & $\begin{array}{c}\text { IT fog which is a new architecture for migrating certain tasks from the data center to the periphery of the } \\
\text { server. The authors present the characteristics of fog computing and the services it can provide in the health } \\
\text { system by ensuring low latency of applications in health services. }\end{array}$ \\
\hline 67 & {$[80]$} & $\begin{array}{c}\text { The IoT remote healthcare monitoring system that provides patient status via a web browser using OS } \\
\text { Contiki with the 6LoWPAN protocol. }\end{array}$ \\
\hline
\end{tabular}

